\title{
Can the triarchic model of psychopathy predict youth offender recidivism?
}

\author{
Pedro Pechorro ${ }^{a, b}$, Jorge Quintas ${ }^{a}$, Matt DeLisi ${ }^{c}$ and Rui Abrunhosa Gonçalves ${ }^{d}$

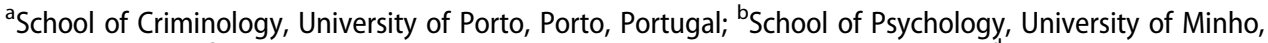

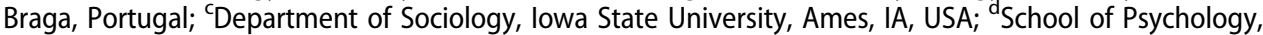 \\ University of Minho, Braga, Portugal
}

\begin{abstract}
The triarchic model of psychopathy is one of the most influential models of psychopathy developed in recent years. The current aim is to investigate the utility of a self-report measure of the triarchic model of psychopathy in predicting criminal recidivism among a sample of incarcerated juvenile offenders. Male youth participants $(N=228, M=16.38$ years, $S D=1.26$ years) from the Detention Centers managed nation-wide by the Ministry of Justice of Portugal were followed during a two-year period and categorized as recidivists or non-recidivists. The Area Under the Curve (AUC) results showed that only the Disinhibition dimension of the triarchic model of psychopathy was able to significantly predict general recidivism. The binary logistic regression models controlling for relevant variables (e.g. age of first detention, past frequency of crimes, conduct disorder symptoms) found that the boldness, meanness, and disinhibition dimensions failed to predict general or violent recidivism. The overall findings suggest that the triarchic model of psychopathy demonstrates limited utility in terms of predicting recidivism among juvenile offenders.
\end{abstract}

\section{ARTICLE HISTORY}

Received 16 January 2020

Accepted 13 July 2020

\section{KEYWORDS}

Crime; detention; recidivism; triarchic model of psychopathy; youth offenders

\section{Introduction}

The Triarchic model of psychopathy is among the most influential models of the construct of psychopathy developed over the last decade (Berg et al., 2017; Evans \& Tully, 2016; Pechorro et al., 2019a). In their seminal paper, Patrick et al.'s (2009) triarchic model advanced boldness, meanness, and disinhibition as the three salient features to the disorder based on their historical review of the psychopathy construct. In this conceptualization, boldness relates to an assertive, socially dominant interpersonal style and venturesomeness where the individual is able to recover quickly from stressful situations, is self-assured, and has a high tolerance for unfamiliarity and danger. Consistent with its general meaning, meanness encompasses callous, cold, cruel, aggressive features of psychopathy and is consistent with the angry, hostile, aggressive, and violent aspects of the disorder. Meanness is consistent with negative emotionality features anger and hostility. According to Patrick (2010), meanness is seen in many behavioral manifestations 
displayed in psychopath's life histories including arrogance and verbal derisiveness, defiance of authority, physical cruelty and various forms of aggression, destructiveness, and the targeted exploitation of others for gain. The third part of their model, disinhibition, relates to impulsivity, irresponsibility, impatience and a general tendency to fail to inhibit one's conduct. It broadly captures the notion that psychopaths have severe self-regulation deficits and are unable to adequately control themselves in a variety of contexts.

Although the balance of research on triarchic psychopathy has focused on measurement and psychometric properties of triarchic measures, a variety of studies examined the differential roles of boldness, meanness, and disinhibition among clinical/correctional samples and among offending and criminal justice system involvement outcomes (e.g. Anestis et al., 2019; Ruchensky et al., 2018; Sellbom et al., 2018). Studies have shown the triarchic model is correlated with antisocial personality features among female prisoners (Sellbom \& Phillips, 2013) and male prisoners (Sellbom et al., 2018), and correlated with antisocial conduct and justice system involvement among persons evaluated at a forensic mental health clinic (Anestis et al., 2019). The limited research on using the triarchic model with forensic and clinical youth samples showed that this model converges with other psychopathy measures and is useful to inform developmental models of conduct problems in adolescence (Laurinavičius et al., 2020; Ruchensky et al., 2018; Sica et al., 2019), but to date it is unknown whether the triarchic model is associated with recidivism among justicesystem involved youth.

Understanding the correlates of recidivism among juvenile delinquents is a matter of pressing practical value (Craig et al., 2019; Trulson et al., 2016). It is well documented that the majority of youth who engage in delinquency do so in a generally normative way that is not usually clinical significant (DeLisi, 2016a, 2016b; Moffitt et al., 2011; Vaughn et al., 2014). However, a subset of juveniles engage in chronic, frequent, and serious delinquency and these are precisely the youth who are most likely to recidivate after release from juvenile custody or release from community sanction. Youth with greater psychopathic features usually have the most extensive and severe delinquent careers including recidivism (Cale et al., 2015; Farina et al., 2018; McCuish et al., 2015; Pechorro et al., 2019).

\section{Present study}

Considering that, to our knowledge, no prior studies have examined the relation between triarchic psychopathy features and criminal recidivism among detained youth offenders we aimed at examining the following research questions: Can the triarchic model of psychopathy predict two-year general and violent recidivism? Can the triarchic model of psychopathy predict two-year general and violent recidivism, after controlling for criminal history?

\section{Method}

\section{Participants}

Male youth detainees from the juvenile detention centers managed nation-wide by the Portuguese General-Directorate of Rehabilitation and Prison Services - Ministry of Justice (DGRSP-MJ) agreed to participate voluntarily in the present investigation $(N=$ 
$228, M_{\text {age }}=16.38$ years, $S D$ age $=1.28$, Range age $\left.=12-19\right)$. The participants were assessed and followed during a two-year period after their release from the detention centers; subsequently they were categorized as recidivists or non-recidivists (see Procedures subsection below). All the participants in the present sample were tried by the court as juveniles according to the Portuguese youth justice law because they were 12-15 years of age when they committed the crimes that led to their detention in the seven nationwide juvenile detention centers. Three years detention per conviction is the hardest measure the courts can apply in Portugal to juvenile offenders.

Most of the participants were Portuguese nationals (84.6\%), came from an urban background (94.3\%), and had low socioeconomic status (96.1\%). Most were of white European white ethnicity (55.7\%) and had completed an average of six years of school education $(M$ education $=6.25$ years, $S D$ education $=1.45$ Range education $=3-10)$. The started committing crimes early in their lives $\left(M_{\text {crime onset }}=11.24\right.$ years, $S D$ crime onset $=2.15$ years $)$, had their 1st problem with the law soon after $\left(M={ }_{1 s t}\right.$ law problem 12.71 years, $S D{ }_{1 \text { st law problem }}=1.87$ years), and were first detained before turning $16\left(M_{\text {first detention }}=15.34\right.$ years, $S D$ first detention $=$ 1.27 years). They also served an average of 628.04 (SD days in detention $=254.32$ ) days in detention before they were released to the community and follow-up.

\section{Measures}

The Youth Psychopathic Traits Inventory - Triarchic - Short (YPI-Tri-S; Pechorro et al., 2019a) is a 21-item brief measure derived from YPI-Triarchic scales that measure the Triarchic model of psychopathy construct (Drislane et al., 2015). The YPI-Tri-S consists of three scales with seven items each, namely: Boldness (e.g. 'I like to do things just for the thrill of it.'), Disinhibition (e.g. 'It often happens that I talk first and think later.'), and Meanness (e.g. 'When other people have problems, it is often their own fault, therefore, one should not help them.'). Each item is scored on an ordinal 4-point Likert scale (ranging from $0=$ Does not apply at all, to $3=$ Applies very well). Scores for each sevenitem group are summed to create the three subscales of the YPI-Tri-S and a total score. Higher scores reflect an increased presence of triarchic psychopathic traits. The psychometric properties of the YPI-Tri-S were previously examined among forensic and school samples of male and female Portuguese youth, and demonstrated adequate validity, reliability and measurement invariance results (Pechorro et al., 2018; Pechorro et al., 2019a; Pechorro et al., 2019b). The recent validation of the YPI-Tri-S in China found support for the utility of the YPI-Tri-S in assessing psychopathy among Chinese male juvenile offenders (Luo et al., 2020). The internal consistency for the present sample was YPI-Tri-S total Cronbach's $a=.83$, Boldness Cronbach's $a=.75$, Disinhibition Cronbach's $a=.72$, and Meanness Cronbach's $a=.70$.

A Conduct disorder (CD) symptoms (APA, 2013) self-report scale was created using the 15 dichotomous criteria that assess the disorder (these were coded $0=$ No, $1=$ Yes; see e.g. Skilling et al., 2001). A total continuous scale score was obtained by summing the aforementioned criteria. Higher scores reflect an increased presence of CD symptoms. Internal consistency for the present sample, estimated by Cronbach's alpha, was $a=.77$. An ad-hoc questionnaire was designed to describe the participants' sociodemographic characteristics, including variables such as age, sex, ethnicity, nationality, urban background, years of education, and socioeconomic status. 


\section{Procedures}

The authors contacted the DGRSP-MJ to obtain permission to conduct the current study, which was granted. Male youth from the Portuguese nation-wide Juvenile Detention Centers were requested to participate voluntarily and informed consent was used. An inclusion criteria was that only participants detained for at least a couple of months could participate because in Portugal youth can be detained temporarily for forensic assessment purposes with no subsequent charges being filled. The rate of participation was about $92 \%$. Some of the assessed participants were not included in the final sample due to several motives (e.g. missing data, transference to adult prisons due to new criminal charges). Data was obtained from official institutional files and self-reports (e.g. age of criminal activity onset). No females were included in the current because very few females are detained in the Portuguese detention centers.

The DGRSP-MJ supplied the official two-year criminal recidivism data of each of the participants (i.e. the follow-up period after release from the nation-wide detention centers), as well as other raw official information (e.g. past crime frequency, diversity, seriousness, violence). An additional 1-year interval was used to guard against potential administrative delays that could cause bias.

Participants who had at least one new criminal charge during the two-year follow-up period leading to a new intervention by the DGRSP-MJ after they were assessed by the authors and released from detention were classified as recidivists. Participants who had no new charges during the two-year follow-up period were classified as non-recidivists. The two-year follow-up period was used because it is the most common time period used to assess youth criminal recidivism (Virginia Department of Juvenile Justice, 2005).

The classification of past violent behaviors was done dichotomously (coded $0=a b s e n t$, $1=$ present) using the operationalization described by Loeber and Farrington (1998). The following examples of violent behaviors were considered: assault with intention to hurt/ kill, armed robbery, gang fighting, strong-arming. The act of carrying a weapon for protection in itself was not considered a violent behavior.

The classification of past crime seriousness was done using a version of the General Delinquency Seriousness Classification (Loeber et al., 1998). This is a 4-level ordinal classification with higher levels reflecting increased seriousness.

The classification of past crime diversity was done according to the six official categories stipulated by the Portuguese Ministry of Justice: crimes against people (e.g. homicide), crimes against property (e.g. shoplifting), crimes against cultural identity (e.g. racism), crimes against living in society (e.g. forced begging), crimes against the State (e.g. money laundering), and (6) diverse legislation crimes (e.g. cannabis planting). This variable can also be treated as non-nominal if each category (coded $0=$ No, $1=$ Yes) is summed to obtain a total score.

\section{Data analytic plan}

The SPSS v26 software (IBM SPSS, 2019) was used to analyze the data of the current study. Area under the curve (AUC) was used to examine the predictive validity of the YPI-Tri-S in terms of general and violent recidivism outcomes. Binary logistic regression was employed to examine the correlations between the predictor variables (i.e. the YPI-Tri-S and its 
dimensions) and the dependent variable (general or violent recidivism). The initial block of each regression model was used to control for crime history variables, and the final block included the YPI-Tri-S total score or the scores of its dimensions. Four regression models were used to predict the two-year general and violent recidivism outcomes. Chi-square tests and ANOVAs were used to compare the groups' sociodemographic and criminal characteristics; effect sizes were included. Associations between the main variables were examined using Pearson correlations (Field, 2013).

\section{Results}

We started our analysis of the results by examining the sociodemographic variables. No significant differences between non-recidivists $(n=127)$ and two-year general recidivists $(n=$ $101 ; 44.3 \%)$, and between non-recidivists and two-year violent recidivists ( $n=44 ; 19.3 \%)$ in terms of age, ethnicity, urban background, nationality, socioeconomic status, and education. Regarding the criminal variables significant differences were found in terms of crime frequency, crime diversity, number of CD symptoms, age of 1st law contact (only significant for the general recidivists), and age of 1st detention. With regard to crime seriousness and to age of first crime committed no differences were found (Table 1).

Next, we examined the correlations between the main variables used in the current study, including the general and violent recidivism outcomes. Most of the correlations among the criminal variables were in the expected directions, including the correlations between the YPI-Tri-S and its dimensions, and between the crime frequency, crime diversity, and crime seriousness variables. However, the correlations between these last three variables and the YPI-Tri-S and its dimensions were almost never significant, and the correlations between the age of first detention variable and the YPI-Tri-S and its dimensions were never significant. Regarding the general recidivism the only significant correlation found was with the Disinhibition dimension. No significant correlations were found between the violent recidivism variable and the YPI-Tri-S total or its dimensions (Table 2).

Presented in Table 3 are the AUCs of the YPI-Tri-S and its dimensions pertaining to twoyear general and violent recidivism. The standard benchmarks stipulate that AUC values $\geq$ .56 represent small effect sizes, AUC values $\geq .64$ represent medium effect sizes, and AUC values $\geq .71$ represent large effect sizes (see Rice \& Harris, 2005). No medium to large effect sizes were detected. However, the YPI-Tri-S total, YPI-Tri-S Boldness, YPI-Tri-S Disinhibition reached the AUC values $\geq .56$ cutoff value for small effect sizes in predicting general recidivism, of which the YPI-Tri-S Disinhibition was the only statistically significant one. In terms of violent recidivism, the YPI-Tri-S Boldness reached the AUC values $\geq .56$ cutoff value for small effect sizes but it was not statistically significant.

Presented in Table 4 are two binary logistic regression models predicting the two-year recidivism outcomes controlling for age of first detention, crime frequency and CD symptoms in the initial step, and then entering the YPI-Tri-S total as the predictor in the final step: general recidivism $\left[\chi_{\mathrm{Omni}}^{2}=27.94(4), p<.001, R_{\mathrm{CS}}^{2}=.12, R_{\mathrm{N}}^{2}=.16, \chi_{\mathrm{HL}}^{2}=8.25(8), p\right.$ $=.41$, Classification $=67 \%$ correct $]$, and violent recidivism $\left[\chi_{\text {Omni }}^{2}=17.26(4), p=.002\right.$, $R_{\mathrm{CS}}^{2}=.10, R_{\mathrm{N}}^{2}=.14, \chi_{\mathrm{HL}}^{2}=8.53(8), p=.38$, Classification $=74 \%$ correct $]$, The YPI-Tri-S total did not significantly predict either general or violent recidivism.

Displayed in Table 5 are two binary logistic regression models predicting the two-year recidivism outcomes controlling for age of first detention, crime frequency and $C D$ 
Table 1. Comparisons of sociodemographic and criminal variables between non-recidivists and general and violent recidivists.

\begin{tabular}{|c|c|c|c|c|}
\hline & Non-recidivists $^{\dagger}$ & Recidivists & Test statistic, $p$ value & Effect size \\
\hline & Non-recidivists $(n=127)$ & General recidivists $(n=101)$ & & \\
\hline Age & $16.46(1.29)$ & $16.27(1.30)$ & $F=1.33, p=.25$ & $\eta_{p}^{2}=.01$ \\
\hline Ethnicity (minorities) & $46.5 \%$ & $41.6 \%$ & $x^{2}=.54, p=.50$ & $\Phi=.05$ \\
\hline Urban background & $96.1 \%$ & $92.1 \%$ & $x^{2}=1.66, p=.25$ & $\Phi=.09$ \\
\hline Nationality & $85.8 \%$ & $83.2 \%$ & $x^{2}=2.98, p=.61$ & $\Phi=.11$ \\
\hline Socioeconomic status & $42.5 \%$ & $42.6 \%$ & $x^{2}=1.36, p=.73$ & $\Phi=.08$ \\
\hline Education (years) & $6.28(1.55)$ & $6.22(1.30)$ & $\hat{F}=.09, p=.77$ & $\eta_{p}^{2}=.00$ \\
\hline Crime frequency & $6.61(6.80)$ & $10.48(8.27)$ & $F=15.02, p<.001$ & $\eta_{p}^{2}=.06$ \\
\hline Crime diversity & $1.85(.70)$ & $2.16(.89)$ & $F=8.52, p=.004$ & $\eta_{p}^{2}=.04$ \\
\hline Crime seriousness & $76.4 \%$ & $81.2 \%$ & $x^{2}=.96, p=.62$ & $\Phi=.07$ \\
\hline CD symptoms & $6.62(3.35)$ & $8.01(3.01)$ & $\hat{F}=10.49, p=.001$ & $\eta_{p}^{2}=.04$ \\
\hline Age of 1st crime & $11.44(2.23)$ & $10.99(2.03)$ & $F=2.47, p=.12$ & $\eta_{p}^{2}=.01$ \\
\hline Age of 1st law problem & $12.94(1.97)$ & $12.44(1.70)$ & $F=4.07, p=.04$ & $\eta_{p}^{2}=.02$ \\
\hline Age of 1st detention & $\begin{array}{l}15.57(1.23) \\
\text { Non-recidivists }(n=127)\end{array}$ & $\begin{array}{l}15.04(1.26) \\
\text { Violent recidivists }(n=44)\end{array}$ & $F=10.37, p=.001$ & $\eta_{p}^{2}=.05$ \\
\hline Age & $16.46(1.29)$ & $16.16(1.32)$ & $F=1.88, p=.17$ & $\eta_{p}^{2}=.01$ \\
\hline Ethnicity (minorities) & $46 \%$ & $38.6 \%$ & $x^{2}=.72, p=.48$ & $\Phi=.07$ \\
\hline Urban background & $96.1 \%$ & $97.7 \%$ & $x^{2}=.28, p=.69$ & $\Phi=.04$ \\
\hline Nationality & $85.7 \%$ & $81.8 \%$ & $x^{2}=2.73, p=.71$ & $\Phi=.13$ \\
\hline Socioeconomic status & $42.9 \%$ & $52.4 \%$ & $x^{2}=1.56, p=.68$ & $\Phi=.10$ \\
\hline Education (years) & $6.28(1.55)$ & $6.27(1.37)$ & $F=.00, p=.99$ & $\eta_{p}^{2}=.00$ \\
\hline Crime frequency & $6.61(6.80)$ & $9.95(7.63)$ & $F=7.72, p=.006$ & $\eta_{p}^{2}=.04$ \\
\hline Crime diversity & $1.85(.70)$ & $2.11(.84)$ & $F=4.13, p=.04$ & $\eta_{p}^{2}=.02$ \\
\hline Crime seriousness & $76.2 \%$ & $88.6 \%$ & $x^{2}=3.33, p=.19$ & $\Phi=.14$ \\
\hline CD symptoms & $6.62(3.35)$ & $7.89(2.99)$ & $F=5.26, p=.02$ & $\eta_{p}^{2}=.03$ \\
\hline Age of 1 st crime & $11.44(2.23)$ & $11.57(1.91)$ & $F=.08, p=.77$ & $\eta_{p}^{2}=.00$ \\
\hline Age of 1st law problem & $12.94(1.97)$ & $12.66(1.71)$ & $F=.72, p=.39$ & $\eta_{p}^{2}=.01$ \\
\hline Age of 1st detention & $15.57(1.23)$ & $15.84(1.22)$ & $F=11.64, p=.001$ & $\eta_{p}^{2}=.07$ \\
\hline
\end{tabular}

Note: $F=$ ANOVA, $X^{2}=$ Chi-square, CD symptoms = Conduct Disorder symptoms; $\eta_{p}^{2}=$ partial eta squared; $\Phi=$ phi.

$\dagger=$ Information in the 'Non-recidivists' column is repeated twice next to the General and the Violent recidivists' information for easy across row comparison.

symptoms in the initial step, and then entering the three YPI-Tri-S dimensions (i.e. Boldness, Disinhibition, and Meanness) as predictors in the final step: general recidivism $\left[\chi_{\text {Omni }}^{2}=29.60(6), p<.001, R_{\mathrm{CS}}^{2}=.12, R_{\mathrm{N}}^{2}=.16, \chi_{\mathrm{HL}}^{2}=16.24(8), p=.039\right.$, Classification $=$ $67 \%$ correct $]$, and violent recidivism $\left[\chi_{\text {Omni }}^{2}=17.59(6), p=.007, R_{\mathrm{CS}}^{2}=.10, R_{\mathrm{N}}^{2}=.15, \chi_{\mathrm{HL}}^{2}=\right.$ 7.18 (8), $p=.52$, Classification $=74 \%$ correct $]$. None of the dimensions of the YPI-Tri-S significantly predicted either general or violent recidivism.

Finally, presented in Table 6 are two binary logistic regression models predicting the two-year recidivism outcomes without controlling for other variables and entering the three YPI-Tri-S dimensions (i.e. Boldness, Disinhibition, and Meanness) as predictors in only one step: general recidivism $\left[\chi_{\mathrm{Omni}}^{2}=5.41(3), p=.14, R_{\mathrm{CS}}^{2}=.02, R_{\mathrm{N}}^{2}=.03, \chi_{\mathrm{HL}}^{2}=8.42\right.$ (8), $p=.39$, Classification $=59.6 \%$ correct $]$, and violent recidivism $\left[\chi_{\text {Omni }}^{2}=1.155\right.$ (3), $p=.76, R_{\mathrm{CS}}^{2}=.01, R_{N}^{2}=.01, \chi_{\mathrm{HL}}^{2}=2.99$ (8), $p=.94$, Classification $=79 \%$ correct $]$. Again, none of the dimensions of the YPI-Tri-S significantly predicted recidivism.

\section{Discussion}

Our study prospectively examined the relationship between self-reported triarchic psychopathic traits of personality and future offending behavior among incarcerated Portuguese 
Table 2. Pearson correlation matrix of the main variables.

\begin{tabular}{|c|c|c|c|c|c|c|c|c|c|c|c|c|c|}
\hline & 1 & 2 & 3 & 4 & 5 & 6 & 7 & 8 & 9 & 10 & 11 & 12 & 13 \\
\hline 1 YPI-Tri-S total & 1 & & & & & & & & & & & & \\
\hline 2 Boldness & $.84^{* * *}$ & 1 & & & & & & & & & & & \\
\hline 3 Disinhibition & $.69^{* * *}$ & $.39 * * *$ & 1 & & & & & & & & & & \\
\hline 4 Meanness & $.79^{* * *}$ & $.55^{* * *}$ & $.25^{* * * *}$ & 1 & & & & & & & & & \\
\hline 5 Crime frequency & .08 & .02 & .09 & .06 & 1 & & & & & & & & \\
\hline 6 Crime diversity & $.15^{*}$ & .09 & .06 & $.19^{*}$ & $.42^{* * *}$ & 1 & & & & & & & \\
\hline 7 Crime seriousness & .02 & .02 & .00 & .02 & $.31^{* * *}$ & $.22^{* *}$ & 1 & & & & & & \\
\hline $8 \mathrm{CD}$ symptoms & $.52^{* * *}$ & $.45^{* * *}$ & $.41^{* * *}$ & $.35^{* * *}$ & $.22^{* *}$ & $.22^{* *}$ & -.12 & 1 & & & & & \\
\hline 9 Age of 1 st crime & $-.23^{*}$ & $-.26^{* * *}$ & $-.16^{*}$ & -.12 & -.04 & -.05 & -.03 & $-.40^{* * *}$ & 1 & & & & \\
\hline 10 Age of 1st law problem & $-.16^{*}$ & $-.16^{*}$ & $-.14^{*}$ & -.07 & -.13 & -.07 & -.01 & $-.34^{* * *}$ & $.63^{* * *}$ & 1 & & & \\
\hline 11 Age of 1 st detention & -.05 & -.08 & -.04 & .01 & $-.21^{* *}$ & .04 & -.10 & -.11 & $.18^{* *}$ & $.33^{* * *}$ & 1 & & \\
\hline 12 General recidivism & .13 & .13 & $.18^{* *}$ & .05 & $.40^{* * *}$ & $.82^{* * *}$ & .07 & $.25^{* * *}$ & $-.15^{*}$ & $-.19^{* *}$ & $-.23^{* * *}$ & 1 & \\
\hline 13 Violent recidivism & .04 & .05 & .01 & .04 & $.34^{* * *}$ & $.62^{* * *}$ & .09 & $.14^{*}$ & .01 & -.09 & $-.20^{* *}$ & $.65^{* * *}$ & 1 \\
\hline
\end{tabular}

Note. YPI-Tri-S = Youth Psychopathic Traits Inventory - Triarchic - Short; CD symptoms = Conduct Disorder symptoms.

${ }^{* * *} p<.001,{ }^{* *} p<.01,{ }^{*} p<.05$. 
Table 3. Predictive validity of the YPI-Tri-S with 2-year general and violent recidivism outcomes.

\begin{tabular}{lcc}
\hline AUC & General recidivism $(95 \% \mathrm{Cl})$ & Violent recidivism $(95 \% \mathrm{Cl})$ \\
\hline YPI-Tri-S total & $.57(.49, .64)$ & $.55(.45, .65)$ \\
YPI-Tri-S Boldness & $.57(.49, .64)$ & $.57(.47, .66)$ \\
YPI-Tri-S Disinhibition & $.59^{*}(.52, .67)$ & $.54(.44, .64)$ \\
YPI-Tri-S Meanness & $.52(.44, .60)$ & $.53(.43, .63)$ \\
\hline
\end{tabular}

Note. YPI-Tri-S = Youth Psychopathic Traits Inventory - Triarchic - Short; AUC = Area under the curve; $95 \% \mathrm{Cl}=95 \%$ Confidence Interval.

* $p<.05$.

Table 4. Regression coefficients of the YPI-Tri-S total predicting 2-year general and violent recidivism.

\begin{tabular}{|c|c|c|c|c|c|}
\hline & $B(\mathrm{SE})$ & Wald & $p$ value & $\operatorname{Exp}(B)$ & $95 \%$ Cl $\operatorname{Exp}(B)$ \\
\hline \multicolumn{6}{|l|}{ 2-year general recidivism } \\
\hline \multicolumn{6}{|l|}{ 1st step } \\
\hline Age of first detention & $-.291(.119)$ & 6.009 & .014 & .748 & $.593, .943$ \\
\hline Past crime frequency & $.061(023)$ & 6.822 & .009 & 1.063 & $1.015,1.113$ \\
\hline CD symptoms & $.108(.045)$ & 5.713 & .017 & 1.114 & $1.020,1.217$ \\
\hline Constant & $2.910(1.871)$ & 2.420 & .120 & 18.360 & \\
\hline \multicolumn{6}{|l|}{$2^{\text {nd }}$ step } \\
\hline Age of first detention & $-.290(.119)$ & 5.995 & .014 & .748 & $.593, .944$ \\
\hline Past crime frequency & $.061(.023)$ & 6.861 & .009 & 1.063 & $1.016,1.113$ \\
\hline CD symptoms & $.103(.053)$ & 3.811 & .050 & 1.108 & $1.000,1.229$ \\
\hline YPI-Tri-S total & $.004(.020)$ & .038 & .846 & 1.004 & $.965,1.044$ \\
\hline Constant & $2.818(1.930)$ & 2.131 & .144 & 16.739 & \\
\hline \multicolumn{6}{|l|}{ 2-year violent recidivism } \\
\hline \multicolumn{6}{|l|}{ 1st step } \\
\hline Age of first detention & $-.415(.157)$ & 7.012 & .008 & .660 & $.486, .898$ \\
\hline Past crime frequency & $.037(.029)$ & 1.602 & .206 & 1.038 & $.980,1.099$ \\
\hline CD symptoms & $.098(.059)$ & 2.792 & .095 & 1.103 & $.983,1.239$ \\
\hline Constant & $4.264(2.444)$ & 3.045 & .081 & 71.084 & \\
\hline \multicolumn{6}{|l|}{$2^{\text {nd }}$ step } \\
\hline Age of first detention & $-.416(.157)$ & 7.008 & .008 & 660 & $.485, .898$ \\
\hline Past crime frequency & $.037(.029)$ & 1.572 & .210 & 1.037 & $.980,1.099$ \\
\hline CD symptoms & $.102(.068)$ & 2.272 & .132 & 1.107 & $.970,1.264$ \\
\hline YPI-Tri-S total & $-.003(.027)$ & .011 & .918 & .997 & $.947,1.051$ \\
\hline Constant & $4.340(2.555)$ & 2.885 & .089 & 76.674 & \\
\hline
\end{tabular}

Note. YPI-Tri-S = Youth Psychopathic Traits Inventory - Triarchic - Short; CD symptoms = Conduct Disorder symptoms.

male juvenile offenders. More specifically the main aims of our study were to investigate whether the triarchic model of psychopathy can predict two-year general and violent recidivism, and whether the triarchic model of psychopathy can predict two-year general and violent recidivism, after controlling for criminal history (e.g. age of first detention) and other relevant variables (e.g. CD symptoms).

Our initial sociodemographic characterization (e.g. age, ethnicity, urban socioeconomic status) of the youth revealed no statistically significant differences between non-recidivists and two-year general recidivists, and between non-recidivists and two-year violent recidivists. Interestingly, our findings do not support previous research indicating that ethnicity is a robust predictor of violent recidivism (e.g. Piquero, Jennings, Diamond, \& Reingle, 2015). With regard to the criminal variables characterization we found several statistically significant differences mostly consistent with prior research (Cottle, Lee, \& Heilbrun, 2001; Cox et al., 2018; Kennedy et al., 2019). General and violent recidivists tended to present higher values crime frequency, diversity and CD symptoms. Moreover, general recidivists tended to present a lower age of first law contact, and violent recidivists tended to present a higher age when their first detention occurred. 
Table 5. Regression coefficients of the YPI-Tri-S dimensions predicting 2-year general and violent recidivism.

\begin{tabular}{|c|c|c|c|c|c|}
\hline & $B(\mathrm{SE})$ & Wald & $p$ value & $\operatorname{Exp}(B)$ & $95 \% \mathrm{Cl} \operatorname{Exp}(\mathrm{B})$ \\
\hline \multicolumn{6}{|l|}{ 2-year general recidivism } \\
\hline \multicolumn{6}{|l|}{ 1st step } \\
\hline Age of first detention & $-.291(.119)$ & 6.009 & .014 & .748 & $.593, .943$ \\
\hline Past crime frequency & $.061(.023)$ & 6.822 & .009 & 1.063 & $1.015,1.113$ \\
\hline $\mathrm{CD}$ symptoms & $.108(.045)$ & 5.713 & .017 & 1.114 & $1.020,1.217$ \\
\hline Constant & $2.910(1.871)$ & 2.420 & .120 & 18.360 & \\
\hline \multicolumn{6}{|l|}{$2^{\text {nd }}$ step } \\
\hline Age of first detention & $-.285(.119)$ & 5.702 & .017 & .752 & $.596, .950$ \\
\hline Past crime frequency & $.063(.024)$ & 7.001 & .008 & 1.065 & $1.017,1.116$ \\
\hline CD symptoms & $.097(.053)$ & 3.355 & .067 & 1.102 & $.993,1.223$ \\
\hline YPI-Tri-S Boldness & $.013(.051)$ & .070 & .792 & 1.014 & $.917,1.120$ \\
\hline YPI-Tri-S Disinhibition & $.049(.048)$ & 1.041 & .308 & 1.050 & $.956,1.153$ \\
\hline YPI-Tri-S Meanness & $-.038(.047)$ & .664 & .415 & .963 & $.879,1.055$ \\
\hline Constant & $2.385(1.961)$ & 1.479 & .224 & 10.862 & \\
\hline \multicolumn{6}{|l|}{ 2-year violent recidivism } \\
\hline \multicolumn{6}{|l|}{ 1st step } \\
\hline Age of first detention & $-.415(.157)$ & 7.012 & .008 & .660 & $.486, .898$ \\
\hline Past crime frequency & $.037(.029)$ & 1.602 & .206 & 1.038 & $.980,1.099$ \\
\hline CD symptoms & $.098(.059)$ & 2.792 & .095 & 1.103 & $.983,1.239$ \\
\hline Constant & $4.264(2.444)$ & 3.045 & .081 & 71.084 & \\
\hline \multicolumn{6}{|l|}{ 2nd step } \\
\hline Age of first detention & $-.413(.158)$ & 6.794 & .009 & .662 & $.485, .903$ \\
\hline Past crime frequency & $.038(.029)$ & 1.658 & .198 & 1.038 & $.981,1.100$ \\
\hline CD symptoms & $.103(.068)$ & 2.297 & .130 & 1.108 & $.970,1.265$ \\
\hline YPI-Tri-S Boldness & $.028(.065)$ & .186 & .667 & 1.028 & $.906,1.167$ \\
\hline YPI-Tri-S Disinhibition & $-.029(.063)$ & .209 & .648 & .972 & $.860,1.099$ \\
\hline YPI-Tri-S Meanness & $-.014(.061)$ & .050 & .823 & .987 & $.876,1.111$ \\
\hline Constant & 4.429 (2.609) & 2.880 & .090 & 83.812 & \\
\hline
\end{tabular}

Note. YPI-Tri-S = Youth Psychopathic Traits Inventory - Triarchic - Short; CD symptoms = Conduct Disorder symptoms.

Table 6. Regression coefficients of the YPI-Tri-S dimensions predicting 2-year general and violent recidivism without controlling for crime history variables.

\begin{tabular}{llccrc}
\hline & \multicolumn{1}{c}{$B(\mathrm{SE})$} & Wald & $p$ value & Exp(B) & $95 \% \mathrm{Cl} \operatorname{Exp}(\mathrm{B})$ \\
\hline 2-year general recidivism & & & & & \\
YPI-Tri-S Boldness & $.038(.047)$ & .658 & .417 & 1.038 & $.948,1.138$ \\
YPI-Tri-S Disinhibition & $.077(.043)$ & 3.130 & .077 & 1.080 & $.992,1.176$ \\
YPI-Tri-S Meanness & $-.021(.044)$ & .225 & .635 & .980 & $.899,1.067$ \\
$\quad$ Constant & $-1.493(.616)$ & 5.875 & .015 & .225 & \\
2-year violent recidivism & & & & & $.948,1.188$ \\
YPI-Tri-S Boldness & $.059(.057)$ & 1.068 & .301 & 1.061 & $.884,1.096$ \\
YPI-Tri-S Disinhibition & $-.016(.055)$ & .086 & .770 & .984 & $.886,1.096$ \\
YPI-Tri-S Meanness & $-.015(.054)$ & .072 & .788 & .986 & .212 \\
$\quad$ Constant & $-1.550(.778)$ & 3.967 & .046 & & \\
\hline
\end{tabular}

Note. YPI-Tri-S = Youth Psychopathic Traits Inventory - Triarchic - Short; CD symptoms = Conduct Disorder symptoms.

Regarding our first research question, using AUC analyses we found that only the Disinhibition dimension significantly predicted recidivism, more specifically general recidivism. However, when considering effect sizes the YPI-Tri-S total, the Boldness dimension, and the Disinhibition dimension obtained a small effect size in terms of predicting general recidivism. The same was valid terms of the Boldness dimension reaching a small effect size regarding violent recidivism. These findings are substantively consistent with Sellbom et al.'s (2018) research that similarly found that it is the Disinhibition dimension of the triarchic model that has the greatest relation to justice system outcomes such 
as recidivism or risk assessment. From a broader perspective, these findings also point to the critical role of behavioral regulation/disinhibition that is inherent in several conceptual models in criminology (e.g. DeLisi \& Vaughn, 2014; Gottfredson \& Hirschi, 1990; Moffitt, 1993).

With regard to our second research question we found that neither the YPI-Tri-S total nor the boldness, meanness, and disinhibition dimensions were able to significantly predict two-year general and violent recidivism after controlling for the age of first detention, past crime frequency, and CD symptoms variables in binary logistic regression analyses. It is worth mentioning that the age of first detention, past crime frequency, and CD symptoms variables were significant predictors of 2-year general recidivism, but only the age of first detention variable was a significant predictor of 2-year violent recidivism. The overall findings showed that the associations with recidivism variables were weak, indicating that perhaps this is an issue with juveniles, and suggest that the triarchic model of personality as measured by the YPI-Tri-S self-report lacks incremental utility in terms of predicting recidivism among serious juvenile offenders.

Some limitations of our study must be pointed out. The measure used in the present study was the YPI-Tri-S (Pechorro et al., 2019a) which is derived from the YPI-Triarchic scales that measure the Triarchic model of psychopathy construct (Drislane et al., 2015). The YPI does not appear to provide an effective pool of items for indexing the boldness construct of the triarchic model due to the lack of items pertaining to the social efficacy and stress immunity facets of boldness, and this can be considered an important limitation (Drislane \& Patrick, 2017). We did not use a measure such as the Triarchic Psychopathy Measure (TriPM; Patrick, 2010), that was specifically designed with the Triarchic model of psychopathy in mind, because we are not aware of any measures of this psychopathy model in youth that were also validated in Portugal. Another limitation was the absence of females from our sample due to the fact very few are incarcerated in the Portuguese juvenile facilities. Another important limitation was that prospective design did not include a final two-year follow-up interview, just the recidivism data provided by the DGRSP-MJ (i.e. the official two-year criminal recidivism data of each of the participants).

The present study also presents some strengths worth mentioning. As far as we are aware this is the first investigation examining the relation between triarchic model of psychopathy and criminal recidivism using a prospective design with a sample of incarcerated male youth offenders that were followed-up during two years. In this regard, we build on prior research that used a sample of juvenile probationers from Lithuania (Laurinavičius et al., 2020) to show that the triarchic model is linked to antisocial behavior across the offender propensity spectrum - spanning community to various adjudicated samples (e.g. probationers, detainees, and inmates) - and based on data from various nations (e.g. Anestis et al., 2019; Luo et al., 2020; Sellbom et al., 2018; Sellbom \& Phillips, 2013). It also addresses a relevant research gap and it advances research by using new data and new measures (Boduszek \& Debowska, 2016). It is also quite pertinent from an ethnic/cross-cultural perspective because it is one of the few that examines the link between psychopathy and recidivism among youth from southern Europe, more specifically Portuguese youth from the Iberian Peninsula (Sullivan \& Kosson, 2006; Zara \& Farrington, 2016). In closing, although there is a proliferation of research on psychopathy and assorted measures of it, we suggest this research is critical to identify the features of psychopathy that are most substantively and significantly associated with conduct problems 
and justice system involvement. This is acutely important when considering juvenile offenders where behavioral interventions provide the most promise in terms of cumulative cost-savings on delinquency.

\section{Acknowledgments}

We are grateful to the Santa Clara, Santo António, Navarro de Paiva, Bela Vista, Mondego, Olivais, and Padre António Oliveira detention centers staff for collaborating with our research.

\section{Compliance with ethical standards}

All procedures performed in studies involving human participants were in accordance with the ethical standards of the institutional and/or national research committee and with the 1964 Helsinki declaration and its later amendments or comparable ethical standards. Informed consent was obtained from all individual participants included in the study.

\section{Disclosure statement}

No potential conflict of interest was reported by the author(s).

\section{Funding}

This work was partially supported by Portuguese Foundation for Science and Technology [grant number UID/PSI/01662/2019].

\section{References}

American Psychiatric Association. (2013). Diagnostic and statistical manual of mental disorders (5th ed.).

Anestis, J. C., Preston, O. C., Harrop, T. M., \& Sellbom, M. (2019). The intersection of sociodemographic characteristics within the nomological network of the triarchic psychopathy model in a forensic sample. Journal of Criminal Justice, 61, 13-25. https://doi.org/10.1016/j.jcrimjus.2019.02.001

Berg, J. M., Lilienfeld, S. O., \& Sellbom, M. (2017). The role of boldness in psychopathy: A study of academic and clinical perceptions. Personality Disorders: Theory, Research, and Treatment, 8(4), 319328. https://doi.org/10.1037/per0000247

Boduszek, D., \& Debowska, A. (2016). Critical evaluation of psychopathy measurement (PCL-R and SRP-III/SF) and recommendations for future research. Journal of Criminal Justice, 44, 1-12.

Cale, J., Lussier, P., McCuish, E., \& Corrado, R. (2015). The prevalence of psychopathic personality disturbances among incarcerated youth: Comparing serious, chronic, violent and sex offenders. Journal of Criminal Justice, 43(4), 337-344. https://doi.org/10.1016/j.jcrimjus.2015.04.005

Cottle, C. C., Lee, R. J., \& Heilbrun, K. (2001). The prediction of criminal recidivism in juveniles: A metaanalysis. Criminal Justice and Behavior, 28(3), 367-394.

Cox, S. M., Kochol, P., \& Hedlund, J. (2018). The exploration of risk and protective score differences across juvenile offending career types and their effects on recidivism. Youth Violence and Juvenile Justice, 16(1), 77-96. https://doi.org/10.1177/1541204016678439

Craig, J. M., Zettler, H. R., Wolff, K. T., \& Baglivio, M. T. (2019). Considering the mediating effects of drug and alcohol use, mental health, and their co-occurrence on the adverse childhood experiencesrecidivism relationship. Youth Violence and Juvenile Justice, 17(3), 219-240. https://doi.org/10.1177/ 1541204018796910 
DeLisi, M. (2016a). Career criminals and the antisocial life course. Child Development Perspectives, 10 (1), 53-58. https://doi.org/10.1111/cdep.12161

DeLisi, M. (2016b). Psychopathy as unified theory of crime. Palgrave Macmillan.

DeLisi, M., \& Vaughn, M. G. (2014). Foundation for a temperament-based theory of antisocial behavior and criminal justice system involvement. Journal of Criminal Justice, 42(1), 10-25. https://doi.org/ 10.1016/j.jcrimjus.2013.11.001

Drislane, L., Brislin, S., Kendler, K., Andershed, H., Larsson, H., \& Patrick, C. (2015). A triarchic model analysis of the youth psychopathic traits inventory. Journal of Personality Disorders, 29(1), 15-41. https://doi.org/10.1521/pedi_2014_28_144

Drislane, L., \& Patrick, C. (2017). Integrating alternative conceptions of psychopathic personality: A latent variable model of triarchic psychopathy constructs. Journal of Personality Disorders, 31(1), 110-132. https://doi.org/10.1521/pedi_2016_30_240

Evans, L., \& Tully, R. J. (2016). The triarchic psychopathy measure (TriPM): Alternative to the PCL-R? Aggression and Violent Behavior, 27, 79-86. https://doi.org/10.1016/j.avb.2016.03.004

Farina, A. S., Holzer, K. J., DeLisi, M., \& Vaughn, M. G. (2018). Childhood trauma and psychopathic features among juvenile offenders. International Journal of Offender Therapy and Comparative Criminology, 62(14), 4359-4380. https://doi.org/10.1177/0306624X18766491

Field, A. (2013). Discovering statistics using IBM SPSS Statistics (4th ed.). Sage.

Gottfredson, M. R., \& Hirschi, T. (1990). A general theory of crime. Stanford University Press.

IBM Corp. (2019). IBM SPSS Statistics for Windows (version 26).

Kennedy, T. D., Edmonds, W. A., Millen, D. H., \& Detullio, D. (2019). Chronic juvenile offenders: Exploring risk factor models of recidivism. Youth Violence and Juvenile Justice, 17(2), 174-193. https://doi.org/10.1177/1541204018770517

Laurinavičius, A., Sellbom, M., Klimukienè, V., Wygant, D. B., Laurinaitytè, I., Ustinavičiūtè, L., \& Baltrūnas, M. (2020). Examination of triarchic psychopathy measure in a sample of Lithuanian juvenile offenders. Psychological Assessment, 32(4), 407-413. https://doi.org/10.1037/pas0000793

Loeber, R., \& Farrington, D. P. (Eds.). (1998). Serious and violent juvenile offenders: Risk factors and successful interventions. Sage Publications.

Loeber, R., Farrington, D. P., Stouthamer-Loeber, M., \& van Kammen, W. B. (1998). Antisocial behavior and mental health problems. Erlbaum.

Luo, J., Wang, M.-C., Zhang, X., Deng, J., Huang, D., \& Zhou, Z. (2020). Psychometric properties of the youth psychopathic traits inventory triarchic scales and its short version in Chinese male juvenile offenders. Journal of Personality Assessment, 1-12. https://doi.org/10.1080/00223891.2020. 1752700

McCuish, E. C., Corrado, R. R., Hart, S. D., \& DeLisi, M. (2015). The role of symptoms of psychopathy in persistent violence over the criminal career into full adulthood. Journal of Criminal Justice, 43(4), 345-356. https://doi.org/10.1016/j.jcrimjus.2015.04.008

Moffitt, T. E. (1993). Adolescence-limited and life-course-persistent antisocial behavior: A developmental taxonomy. Psychological Review, 100(4), 674-701. https://doi.org/10.1037/0033-295X.100. 4.674

Moffitt, T. E., Arseneault, L., Belsky, D., Dickson, N., Hancox, R. J., Harrington, H., Houts, R., Poulton, R., Roberts, B. W., Ross, S., Sears, M. R., Thomson, W. M., \& Caspi, A. (2011). A gradient of childhood selfcontrol predicts health, wealth, and public safety. Proceedings of the National Academy of Sciences of the United States of America, 108(7), 2693-2698. https://doi.org/10.1073/pnas.1010076108

Patrick, C. (2010). Conceptualizing the psychopathic personality: Disinhibited, bold, ... or just plain mean? In R. T. Salekin, \& D. R. Lynam (Eds.), Handbook of child \& adolescent psychopathy (pp. 15-48). The Guilford Press.

Patrick, C., Fowles, D., \& Krueger, R. (2009). Triarchic conceptualization of psychopathy: Developmental origins of disinhibition, boldness, and meanness. Development and Psychopathology, 21(3), 913-938. https://doi.org/10.1017/S0954579409000492

Pechorro, P., Braga, T., Ray, J., Gonçalves, R., \& Andershed, H. (2019). Do incarcerated male juvenile recidivists differ from first-time offenders on self-reported psychopathic traits? A retrospective study. European Journal of Criminology, 16(4), 413-431. https://doi.org/10.1177/ 1477370818772774 
Pechorro, P., DeLisi, M., Alberto, I., Ray, J., \& Simões, M. (2019a). The triarchic model of psychopathy among incarcerated male youths: A psychometric study. In M. DeLisi (Ed.), Routledge International Handbook of psychopathy and crime (pp. 265-275). Routledge.

Pechorro, P., DeLisi, M., Ray, J., Alberto, l., \& Simões, M. (2019b). A brief measure of the triarchic model of psychopathy among community youths: Psychometrics and measurement invariance. Psychology, Crime and Law, 25(10), 977-999. https://doi.org/10.1080/1068316X.2019.1597095

Pechorro, P., Simões, M., Alberto, I., \& Ray, J. (2018). Triarchic model of psychopathy: A brief measure among detained female youths. Deviant Behavior, 39(11), 1497-1506. https://doi.org/10.1080/ 01639625.2018.1487171. ISSN: 0163-9625.

Piquero, A. R., Jennings, W. G., Diamond, B., \& Reingle, J. M. (2015). A systematic review of age, sex, ethnicity, and race as predictors of violent recidivism. International Journal of Offender Therapy and Comparative Criminology, 59(1), 5-26.

Rice, M., \& Harris, G. (2005). Comparing effect sizes in follow-up studies: ROC Area, Cohen's d, and r. Law and Human Behavior, 29(5), 615-620. https://doi.org/10.1007/s10979-005-6832-7

Ruchensky, J. R., Edens, J. F., Donnellan, M. B., Hawes, S. W., \& Mulvey, E. P. (2018). A comparison of the youth psychopathic traits inventory (YPI)- triarchic scales and the YPI in a sample of justiceinvolved youth. Journal of Personality Disorders, 34, 308-323. https://doi.org/10.1521/pedi_ 2018_32_399

Sellbom, M., Laurinavičius, A., Ustinavičiūtè, L., \& Laurinaitytė, I. (2018). The triarchic psychopathy measure: An examination in a Lithuanian inmate sample. Psychological Assessment, 30(7), e10e20. https://doi.org/10.1037/pas0000603

Sellbom, M., \& Phillips, T. R. (2013). An examination of the triarchic conceptualization of psychopathy in incarcerated and nonincarcerated samples. Journal of Abnormal Psychology, 122(1), 208-214. https://doi.org/10.1037/a0029306

Sica, C., Ciucci, E., Baroncelli, A., Frick, P., \& Patrick, C. J. (2019). Not just for adults: Using the triarchic model of psychopathy to inform developmental models of conduct problems in adolescence. Journal of Clinical Child \& Adolescent Psychology, 1-15. https://doi.org/10.1080/15374416.2019. 1574228

Skilling, T., Quinsey, V., \& Craig, W. (2001). Evidence of a taxon underlying serious antisocial behavior in boys. Criminal Justice and Behavior, 28(4), 450-470. https://doi.org/10.1177/009385480102800404

Sullivan, E., \& Kosson, D. (2006). Ethnic and cultural variations in psychopathy. In C. J. Patrick (Ed.), Handbook of Psychopathy (pp. 437-458). Guilford Press.

Trulson, C. R., Haerle, D. R., Caudill, J. W., \& DeLisi, M. (2016). Lost causes: Blended sentencing, second chances, and the Texas youth commission. University of Texas Press.

Vaughn, M. G., Salas-Wright, C. P., DeLisi, M., \& Maynard, B. R. (2014). Violence and externalizing behavior among youth in the United States: Is there a severe $5 \%$ ? Youth Violence and Juvenile Justice, 12(1), 3-21. https://doi.org/10.1177/1541204013478973

Virginia Department of Juvenile Justice. (2005). Juvenile recidivism in Virginia. DJJ Research Quarterly, $3,1-12$.

Zara, G., \& Farrington, D. P. (2016). Criminal recidivism: Explanation, prediction and prevention. Routledge. 